Perspective paper

Biogenic and biomimetic carriers as versatile transporters to treat infections

Adriely Goes and Gregor Fuhrmann*

Helmholtz-Institute for Pharmaceutical Research Saarland (HIPS), Helmholtz-Centre for Infection

Research (HZI), Biogenic Nanotherapeutics group (BION), Campus E8.1, 66123 Saarbrücken

Department of Pharmacy, Saarland University, Campus Building E8.1, 66123 Saarbrücken, Germany

*Corresponding author, phone: +49 68198806 1500, email: gregor.fuhrmann@helmholtz-hzi.de,

ORCID ID G. Fuhrmann: 0000-0002-6688-5126

ORCID ID A. Goes: 0000-0003-2629-6068 


\section{Key words and definitions:}

nanoantibiotics - encapsulation of antibiotic drugs into nanocarriers to improve their targeted delivery and reduce unspecific tissue accumulation and side-effects

biogenic drug delivery - subsection of drug delivery technologies taking advantage of principles and systems present in nature; systems often exhibit beneficial properties such as reduced immunogenicity or inherent targeting abilities

biomimetics - imitating natural principles and systems by using synthetic building blocks and mechanisms

bio-inspired delivery systems - semi-synthetic drug carriers or delivery methods that take inspiration from natural principles, e.g., liposomes

extracellular vesicles - cell-derived natural nanoparticles produced by almost any mammalian cell in vitro and in vivo; serve for intercellular communication between neighboring cells and at distance

outer membrane vesicles - bacteria-derived nanoparticles shed from the outer membrane; vesicles transfer information within bacterial colonies but may also be used to attack other bacteria during the fight for an environmental niche

cell-mimetics - biomimetic approaches resembling function and structure of living cells

virus-like particles - multi-protein assemblies carrying structure and characteristics of viruses; currently under investigation as safe and versatile vaccine approach 
Biogenic and biomimetic therapeutics are a relatively new class of systems that are of physiological origin and/or take advantage of natural pathways, or aim at mimicking these to improve selective interaction with target tissue. The number of biogenic and bioengineered avenues for drug therapy and diagnostics has multiplied over the past years for many applications, indicating the high expectations associated with this biological route. Nevertheless, the use of "bio"-related approaches for treating or diagnosing infectious diseases is still rare. Given that infectious diseases-in particular bacterial resistances - are seriously on the rise, there is an urgent need to take advantage of biogenic and bioengineered systems to target these challenges. In this manuscript, we first give a definition of the various "bio" terms, including biogenic, biomimetic, bio-inspired and bioengineered and we highlight them using tangible applications in the field of infectious diseases. Our examples cover cell-derived systems, including bioengineered bacteria, virus-like particles and different cell-mimetics. Moreover, we discuss natural and bioengineered particles such as extracellular vesicles from mammalian and bacterial sources, and liposomes. A concluding section outlines the potential for biomaterial-related avenues to overcome challenges associated with difficult-to-treat infections. We critically discuss benefits and risks for these applications and give an outlook on the future of biogenic engineering. 


\section{Biogenic, bio-inspired and bioengineered systems - a definition}

In recent years, drug therapy and diagnostic avenues that take advantage of biological systems or natural (biogenic) principles have rapidly multiplied. Indeed, nature is the ideal prototype for developing novel approaches for selectively delivering compounds ${ }^{1}$ or detecting physiological markers in a highly sensitive way. ${ }^{2}$ These new systems take advantage of natural pathways or may mimic these in order to optimize physiological interactions with tissue or target cells, and ultimately enhancing therapeutic performance in clinical trials. ${ }^{3}$ Such natural principles of selective cell recognition have evolved over time to maximize functionality and selectivity, thus offering a stronger specificity than purely synthetic systems. The nomenclature for these nature-related and natureinspired systems is diverse manifold and ranges from "biogenic" and "biomimetics", to "bio-inspired" or "bioengineered" (Figure 1).

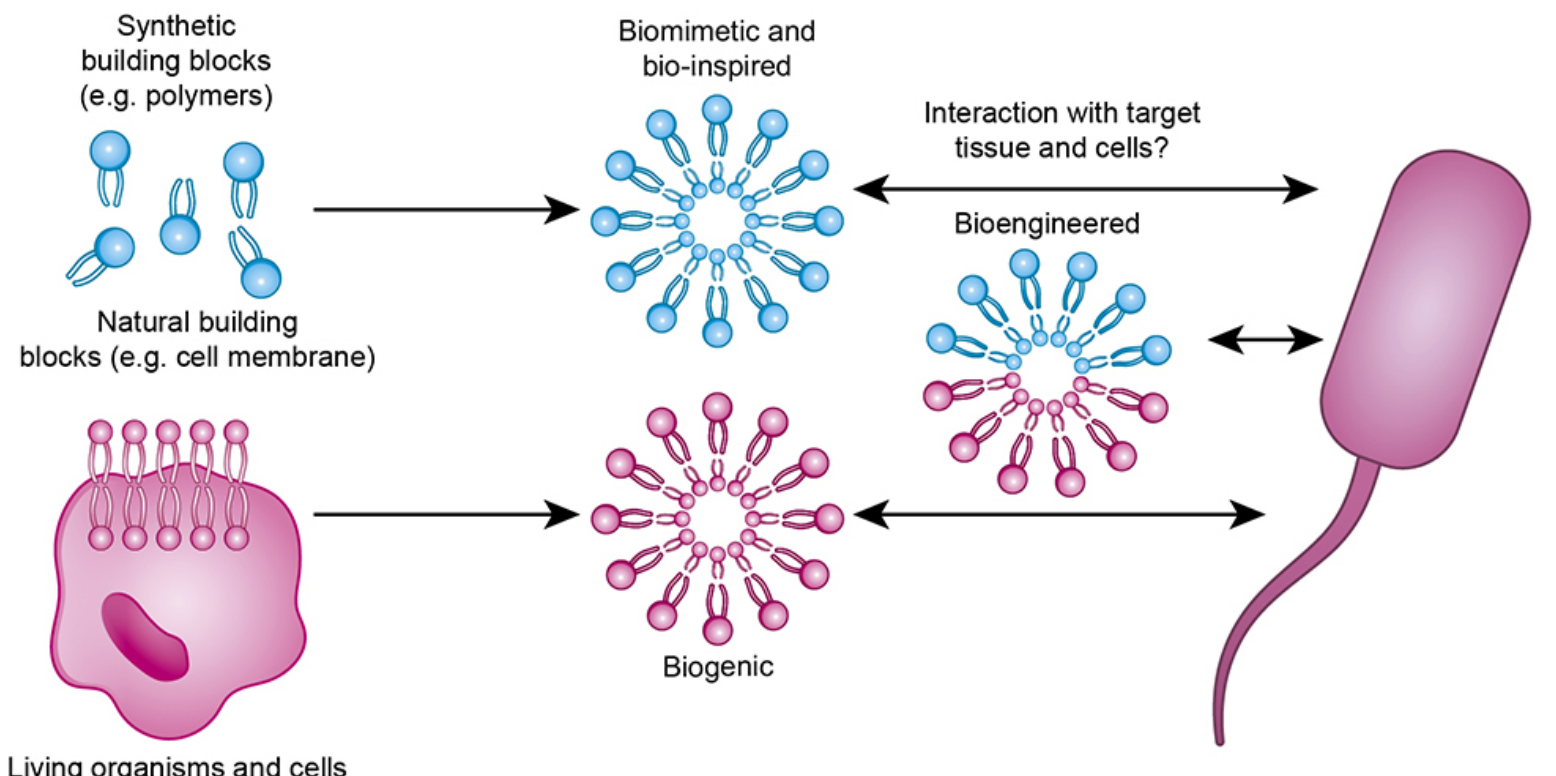

Figure 1. Differences in origin of various "bio" systems. Living cells and organisms produce biogenic entities, such as cells or cell-derived vesicles which in nature serve a specific function, a process that may be utilized to deliver compounds in a specific manner. In comparison, biomimetic and bio-inspired systems are synthetic and artificial approaches that imitate physiological model systems or biological processes. Successful examples for synthetic biomimetic approaches are liposomal or polymeric carriers. When biogenic and biomimetic systems are combined, bioengineered avenues are developed. These systems are based on the application of engineering approaches on biological and medical building blocks, such as semisynthetic polymer-drug conjugates or functionalized natural vesicles. Overall, "bio"-systems are thought to possess better interactions with cells and living tissue rendering them promising avenues for targeted anti-infectives' delivery or detection of bacterial and viral illnesses. 
In the field of targeted drug delivery, the use of such "bio"-systems may be advantageous compared to chemically inert drug carriers or materials, which merely serve as the matrix in which an active compound is embedded. In contrast, biogenic and bioengineered approaches are postulated to lead to an active interplay of the carrier system with the biology encountered in the human body and will additionally enhance the drug activity or diagnostic readout in a physiological manner. Moreover, compared to their artificial counterparts, such natural approaches may reduce recognition by the immune system, diminished complement activation, and minimized accumulation in other tissue. ${ }^{4}$ In return, reduced side-effects, enhanced localized drug concentration at the site of action and thus augmented therapeutic outcome may be observed. For these reasons, biogenic and bioengineered avenues are promising future alternatives to purely synthetic systems which often show limited efficacy in (pre)clinical assessments. ${ }^{3}$

In the present perspective article, we first aim to define and differentiate between the various "bio"-terms and discuss advantages of each approach (Box 1). We subsequently give an overview of current biogenic and bio-inspired systems for the selective therapy and detection of bacterial infections. Difficult-to-treat infections are an increasing healthcare problem world-wide and we thus discuss the potential of bio-avenues to target these emerging problems.

\section{Box 1. Definitions of biogenic, biomimetic/bio-inspired and bioengineered approaches.}

\section{Glossary - What are similarities and differences between the "bio" terms?}

Biogenic - produced or originating from a living organism

Any cell, particle or compound that is derived from cells or living tissues; e.g., erythrocytes, extracellular vesicles or enzymes.

The complexity of biogenic systems may hinder their (semi)synthetic replication but they give a competitive edge due to their physiological role in translating biological interactions.

Biomimetic and bio-inspired - imitation of model systems and elements of nature and natural processes

Mostly synthetic and artificial model systems or approaches that take inspiration from natural principles and mechanisms; e.g., liposomes, artificial viruses, synthetic peptides.

The level of complexity is often reduced in order to create simple systems that resemble the most important principles of their natural archetype.

Bioengineered - biological and medical application of engineering methods and techniques

Combinations of natural building blocks with artificial counterparts or the utilization of engineering 
approaches on physiological systems; e.g., functionalization of cells, cell/bacterio-mimetics, drugpolymer conjugates.

By using known engineering methods, the degree of complexity for manufacturing these systems is substantially diminished but without compromising on their natural and selective interaction with living cells and tissue.

\section{Biogenic as promising option for anti-infective avenues}

There is an urgent need to develop new treatment options for resistant and multi-resistant pathogens, in particular bacteria. The number deaths induced by these difficult-to-treat infections is currently estimated to be up to 25,000 per year in Europe, with an even larger number of affected patients worldwide. ${ }^{5}$ In the UK 2014 Review on Antimicrobial Resistance, it was estimated that by 2050 an incredible number of 10 million deaths per year worldwide will be caused by those bacteria, exceeding the incidence of cancer-associated deaths (www.amr-review.org.). The World Health Organization (WHO) has recently published a list of highly relevant pathogens for which novel therapeutic approaches need to be developed. Among these are several multi-drug resistant bacteria including Pseudomonas, Acinetobacter and different types of Enterobacteriaceae, that often cause problems in hospitals, nursing homes and among patients with medical devices (www.who.int). One way of addressing the challenging question of how to tackle problem bacteria is still the discovery of novel antibiotic compounds. ${ }^{6}$ In recent years, a few promising candidates and novel targets have been developed, such as lectin inhibitors ${ }^{7}$ and drugs interfering with the bacterial quorum sensing system. ${ }^{8}$ Such novel drugs represent powerful new ways to target resistant bacteria, but efficient carriers for their selective delivery are needed in order to increase tissue specific delivery. Encapsulation of antibiotics into nanoparticulate drug delivery systems, such as liposomes, create so-called "nanoantibiotics," which improve drug transport to the site of infection, enhance antibiotic uptake into bacteria, and increase overall antibiotic efficiency. ${ }^{9}$ Nanoparticles are among the most promising avenues to allow existing antibiotics to reach their site of action, thereby enhancing anti-infective

strength and overcome certain types of microbial drug resistance, such as efflux pumps. ${ }^{10}$ Nevertheless, the ability of current nanoantibiotics to exclusively target pathogenic bacteria is often insufficient, as their stability under physiological conditions is suboptimal and they may induce sideeffects due to their synthetic origin. Biogenic approaches offer the potential to counterbalance the 
drawbacks of artificial carriers, as they may naturally overcome barriers associated with anti-infective therapy. Biogenic avenues provide exciting opportunities to develop novel future concepts for enhanced-sensitivity diagnostics. ${ }^{11}$

Several bacteria that are considered traditionally as extracellular pathogens have now been investigated also as intracellular pathogens not only in professional phagocytes (e.g. macrophages) but in non-professional phagocytes (e.g. epithelial cells). The pathogen becomes intracellular as a strategy to evade the immune system and treatment with antibiotics. The main example of such pathogens is Staphylococcus aureus. ${ }^{12}$ Besides becoming intracellular, bacteria can also form biofilms. Biofilms are small colonies of bacteria inserted in extracellular matrix, where they became stable and tolerant to antimicrobial treatment and the immune system. ${ }^{13}$ It has been reported that biofilms can incorporate different species of bacteria, such as Staphylococcus aureus and Pseudomonas aeruginosa together. ${ }^{14}$ Co-infection and biofilm formation are especially important in cases of chronic pulmonary disease (e.g. cystic fibrosis) ${ }^{15}$, making the infection hard to be treated and deteriorating the condition of the patient clinically. When using nanodelivery approaches, a major challenge is to overcome or disrupt this rigid biofilm barrier and to reach the underlying pathogens. ${ }^{16}$

Here we summarize recent efforts using natural systems and - as this is an emerging field of research - we focus specifically on publications and reports from 2013 onwards (Table 1). We emphasize biogenic and bioengineered approaches (i.e. avenues that are fully or partially based on natural components or entities) but we also highlight a few very important examples of bioinspired avenues, as we believe that mimicking physiological elements is crucial for an optimal drug transfer with minimal side effects (Figure 2). Fully synthetic approaches are beyond the scope of this work but are summarized in a comprehensive recent review. ${ }^{17}$ Nevertheless, combining biogenic with artificial systems may in the future lead to enhanced semi-synthetic avenues where both approaches may benefit from one another. The approaches in this manuscript are organized by cell-derived systems, natural and bioengineered nanocarriers, followed by a concluding section on bio-inspired materials and their importance in the future of this field of research. 


\begin{tabular}{|c|c|c|c|c|c|}
\hline Representation & Type of carrier & Method & Results & $\begin{array}{l}\text { Referenc } \\
\text { e }\end{array}$ & Year \\
\hline & $\begin{array}{l}\text { Magnetotactic } \\
\text { bacteria } \\
\text { biohybrid } \\
\text { microswimmers. }\end{array}$ & $\begin{array}{l}\text { Non-pathogenic magn etotactic } \\
\text { bacteria (Magnetosopirrillum } \\
\text { gryphiswalense, MSR-1) } \\
\text { integrated with ciprofloxacin- } \\
\text { loaded mesoporous silica } \\
\text { microtubes; resulting in } \\
\text { controllable "microswimmers" } \\
\text { (biohybrids). } \\
\end{array}$ & $\begin{array}{c}\text { Biohybrid system able to } \\
\text { be magnetically guided } \\
\text { through } E \text {. coli biofilms, } \\
\text { delivering the } \\
\text { ciprofloxacin cargo. }\end{array}$ & 18 & 2017 \\
\hline & $\begin{array}{l}\text { Non-viral } \\
\text { nanoparticles } \\
\text { mimicking virus } \\
\text { surface } \\
\text { topography. }\end{array}$ & $\begin{array}{l}\text { Negatively charged silica } \\
\text { nanoparticles (NPs) modified } \\
\text { with amine groups or } \\
\text { polyethylenimine (PEI) to } \\
\text { become positively charged; } \\
\text { attachment of smaller silica NPs } \\
\text { resulting in NPs with a rough } \\
\text { surface. }\end{array}$ & $\begin{array}{l}\text { Higher cellular uptake in } \\
\text { HeLa cells compared to } \\
\text { smooth carriers. }\end{array}$ & 19 & 2013 \\
\hline & $\begin{array}{l}\text { Virus-like } \\
\text { particles (VLPs) } \\
\text { of bacteriophage } \\
\text { MS2 to deliver } \\
\text { NPs, drugs, } \\
\text { siRNA and } \\
\text { proteins. }\end{array}$ & $\begin{array}{l}\text { MS2 VLPs surface modified with } \\
\text { a HCC (human hepatocellular } \\
\text { carcinoma)-specific peptide } \\
\text { (SP94), a fusogenic peptide and } \\
\text { PEG-1000; MS2 VLPs further } \\
\text { modified with histidine-rich } \\
\text { fusogenic peptide (H5WYG). }\end{array}$ & $\begin{array}{l}\text { Targeted VLPs deliver } \\
\text { drugs, siRNA, protein } \\
\text { toxins, and quantum dots } \\
\text { to HCC; SP94-targeted } \\
\text { VLPs rapidly internalized } \\
\text { by HCC but not by } \\
\text { normal hepatocytes; } \\
\text { Particles further modified } \\
\text { with H5WYG promoted } \\
\text { endosomal escape. }\end{array}$ & 20 & 2011 \\
\hline & $\begin{array}{c}\text { Genetically } \\
\text { engineered } \\
\text { hepatitis B core } \\
\text { VLPs loaded } \\
\text { with } \mathrm{Fe}_{3} \mathrm{O}_{4} \text { NPs. }\end{array}$ & $\begin{array}{l}\text { Functional particles encapsulated } \\
\text { into VLPs through histidine tags } \\
\text { affinity for nickel- nitrilotriacetic } \\
\text { acid (NTA) chelate. }\end{array}$ & $\begin{array}{l}\text { Increased uptake in HeLa } \\
\text { cells compared to pure } \\
\mathrm{Fe}_{3} \mathrm{O}_{4} \text { nanoparticles. }\end{array}$ & 21 & 2015 \\
\hline & $\begin{array}{l}\text { Polystyrene NPs } \\
\text { attached to the } \\
\text { surface of red } \\
\text { blood cells } \\
\text { (RBC } \\
\text { hitchhiking). }\end{array}$ & $\begin{array}{l}\text { Polystyrene NPs incubated at } \\
\text { varying particle to RBC ratios. }\end{array}$ & $\begin{array}{l}\text { NP-Attachment to RBCs } \\
\text { at low doses did not } \\
\text { affect circulation time, } \\
\text { avoided mononuclear } \\
\text { phagocyte system (MPS) } \\
\text { and enabled delivery to } \\
\text { difficult-to-reach tissues. }\end{array}$ & 22 & 2013 \\
\hline & $\begin{array}{l}\text { Nanoparticle in } \\
\text { situ hitchhiking } \\
\text { activated } \\
\text { neutrophils. }\end{array}$ & $\begin{array}{l}\text { Intravenous administered albumin } \\
\text { NPs specifically internalized by } \\
\text { activated neutrophils. }\end{array}$ & $\begin{array}{c}\text { NP-Neutrophils } \\
\text { transmigrated across } \\
\text { blood vessel wall and in } \\
\text { response to inflammation } \\
\text { induced by the pathogen } \\
\text { invasion. }\end{array}$ & 23 & 2015 \\
\hline & $\begin{array}{l}\text { Extracellular } \\
\text { vesicles (EVs) } \\
\text { and outer } \\
\text { membrane } \\
\text { vesicles } \\
\text { (OMVs). }\end{array}$ & $\begin{array}{l}\text { EVs and OMVs isolated by } \\
\text { filtration, ultracentrifugation, } \\
\text { density gradients, } \\
\text { immunoaffinity, gel } \\
\text { chromatography and } \\
\text { commercially available kits. }\end{array}$ & $\begin{array}{l}\text { Potential long distance } \\
\text { targeting; intrinsically } \\
\text { compatible; high } \\
\text { targeting efficacy. }\end{array}$ & 24,25 & $\begin{array}{l}2015 \\
2017\end{array}$ \\
\hline
\end{tabular}




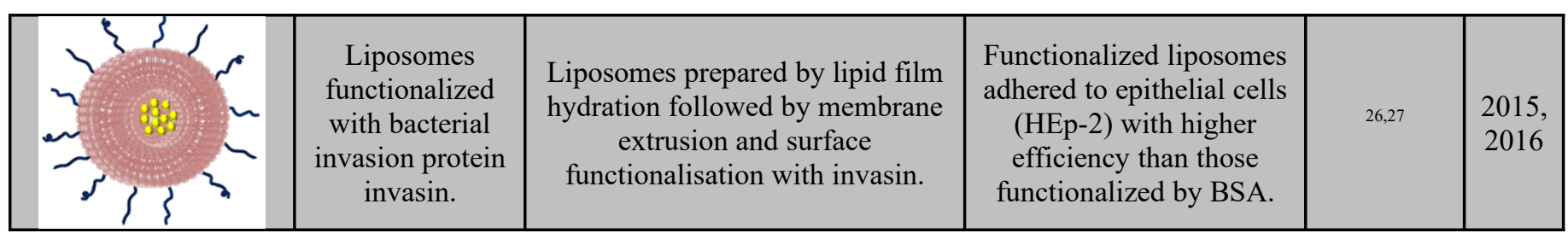

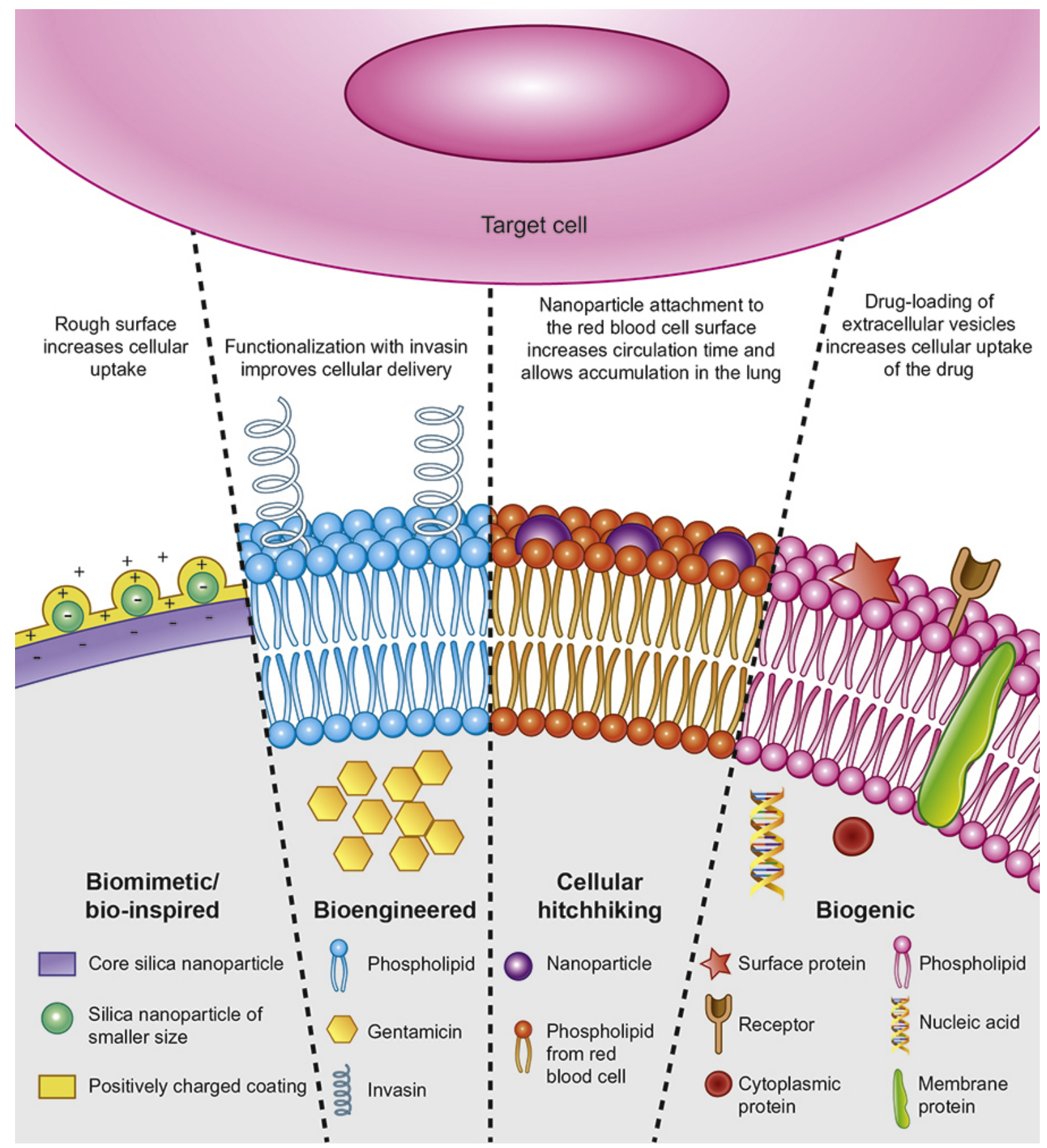

Figure 2. Schematic overview of selected biogenic and bioengineered avenues for targeting infections. Approaches for biomimetic, bioengineered, cellular hitchhicking and biogenic avenues are displayed. Biomimicry may take advantage of reproducing the rough surface of viruses by coating larger core particles with smaller nanoparticles, both made of silica. Such rough surface may enhance cellular uptake in a comparable manner to viruses. Surface bioengineering of plain liposomes with a bacterial invasion protein (invasin) rendered bacterio-mimetic carriers for enhanced targeting of difficult-to-reach intracellular pathogens. Nanoparticles may also be coupled onto the surface of red 
blood cells to employ them for cellular hitchhiking. Erythrocytes possessed enhanced systemic circulation time and may shuttle their backpack-cargo to the narrow vasculature in the lungs. Finally, extracellular vesicles are currently under investigation as potentially biocompatible and cell-selective carriers. These biogenic particles are derived from all cells and subsequently are of natural composition, making them promising in the field of targeted drug delivery.

\section{- Cell-derived systems for delivery of anti-infective compounds}

\section{Bioengineered bacteria}

The motility of flagellated bacteria can be utilized to deliver molecules to areas of difficult reach. Taherkhani and collaborators developed a magnetotactic bacteria-nanoliposome complex as a drug delivery system. ${ }^{28}$ Using Magnetococcus marinus MC-1 magnetotactic bacteria (MTB), nanoliposomes (LP) were covalently bound to their surfaces without impairing the bacteria's motility. Their results show that the MTB-LP complex is rapidly internalized by phagocytic cells (J774), while the opposite is seen for non-phagocytic cells (NIH/3T3 mouse fibroblasts and Colo 205 human metastatic colon cells). ${ }^{28}$ Although this concept is focused on delivery of cytotoxic compounds, it may be translated to infectious diseases by encapsulation of liposomes with antibiotic drugs. Moreover, the potential of this bacterial self-propeller could be further enhanced when drug-loaded nanoliposomes are detached in a specific tissue and/or following a stimulus such as $\mathrm{pH}$ decrease during infections.

In an infection setting, Stanton and coworkers recently used the magnetotactic flagellated bacteria Magnetosopirrillum gryphiswalense (MSR-1). MSR-1 was integrated into mesoporous silica microtubes loaded with ciprofloxacin by incubation in a buffer solution, resulting in a magneticallyresponsive biohybrid system. ${ }^{18}$ The biohybrid system was tested against Escherichia coli biofilms and was shown to be able to be magnetically guided into them. The acidic biofilm microenvironment was instrumentalized for a selective drug release (Figure 3.). This system is interesting for its ability to physically penetrate and attack the biofilms, contributing to their disruption. However, further study is needed on biocompatibility and on elucidating how many biohybrids need to be administered to reach therapeutic levels of antibiotics at the site of infection. In a similar approach, Park and collaborators loaded doxorubicin into polyelectrolyte multilayer (PEM) microparticles with embedded magnetic nanoparticles and then attached to the E. coli surface, successfully guiding them to a specific target. ${ }^{29}$ 
Translating this guided approach to human patients may be challenging. Nevertheless, taking advantage of magnetotactic bacteria and carrier systems is an innovative and promising approach to deliver drugs to a specific site and consequently optimize the therapy and avoid adverse effects caused by drugs.

\section{Viruses and virus-like particles}

Viruses have an excellent ability to avoid the immune system and invade cells to "unload" their genes and replicate. ${ }^{1}$ Several research groups have been exploiting this ability of the viruses to develop carriers that mimic their behavior but without the risk of inducing infections. These approaches include developing nanoparticles mimicking the natural virus-surface and virus-like particles that resemble viral structures without being infectious. For example, enveloped viruses have a size of $30-400 \mathrm{~nm}$, which is adequate for uptake by cells, and their surface is rough with glycoprotein spikes. ${ }^{19}$ In an attempt to investigate the role of this surface roughness on the cellular delivery efficiency, excluding the receptor-specific interactions influence, Niu and collaborators prepared negatively charged silica nanoparticles which were coated with positively charged amine groups and polyethylemine, resulting in a positively charged nanoparticle. In addition, negatively charged small diameter silica particles were prepared separately and bound to the larger nanoparticles prepared previously. The resulting particle had a rough surface, mimicking those of viruses. ${ }^{19}$ Particles with a rough surface showed a better binding ability and a 5.6 times higher cellular uptake in HeLa cells compared to smooth nanocarriers. These results indicate that rough particles mimicking natural viruses enhance the interaction at the cellular level, which may be an important consideration during design of anti-infective nanocarriers. It remains to be determined whether enhanced uptake of such rough particles does also improve the delivery of loaded anti-infective cargo. 

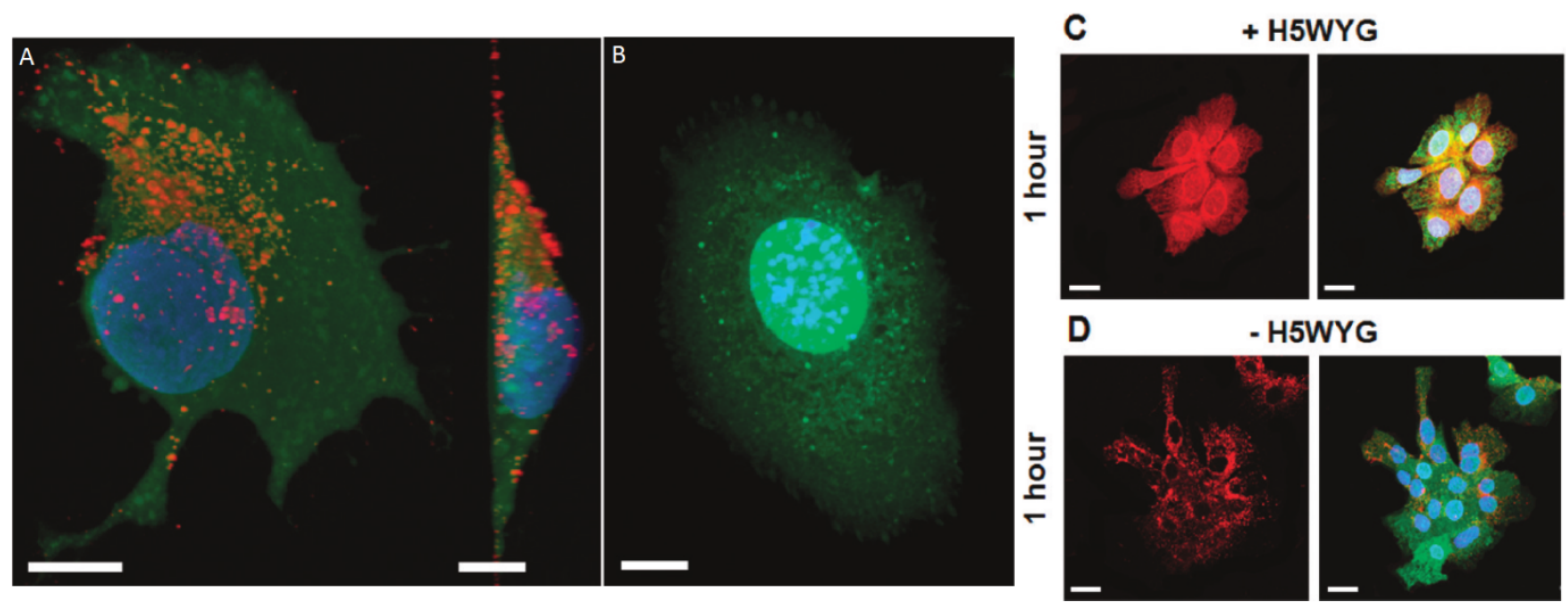

Figure 3. (A and B) Confocal fluorescence microscopy images showing that SP94-targeted VLPs (red) are internalized by Hep3B (A) but not by hepatocytes (B). (C and D) VLPs comodified with the SP94 targeting peptide and the H5WYG fusogenic peptide become distributed in the cytosol of Hep3B cells, while VLPs modified with only SP94 remain in the endosomes. Hep3B cells exposed to SP94-targeted VLPs (red) for 1 hour. VLPs were comodified with 60 SP94 peptides/particle and $\sim 75 \mathrm{H} 5 \mathrm{WYG}$ peptides/particle in panel $\mathrm{C}$, while they were modified with only $\sim 60$ SP94 peptides/particle in D. Scale bars: $10 \mu \mathrm{m}$. Reprinted with permission from Ashley, C. E., Carnes, E. C., Phillips, G. K., Durfee, P. N., Buley, M. D., Lino, C. A., Padilla, D. P., Phillips, B., Carter, M. B., Willman, C. L., Brinker, C. J., Caldeira, J. D. C., Chackerian, B., Wharton, W., and Peabody, D. S. (2011) Cell-specific delivery of diverse cargos by bacteriophage MS2 virus-like particles. ACS Nano 5, 5729-5745. Copyright 2011 American Chemical Society.

Such specific delivery of drugs loaded into bioengineered virus-like particles (VLPs) was investigated by Ashley and colleagues, who developed an interesting strategy to transfer a variety of molecules to specific targets. Producing VLPs from bacteriophages MS2 and modifying their surfaces with a peptide (SP94) that binds to human hepatocellular carcinoma (HCC), they showed that the VLPs have a higher avidity to HCC when compared to normal hepatocytes (Figure 3. A and B), endothelial cells (HUVECs), and immune cells such as T-lymphocytes. ${ }^{20}$ They also demonstrated that with further modification of the VLPs with histidine-rich fusogenic peptide (H5WYG), it is possible to avoid the endosomal pathway, allowing the VLPs to be dispersed in the cytosol (Figure 3. C and D). ${ }^{20}$ This approach has potential to be adapted to deliver antimicrobial drugs to specific targets by surface modification.

The concept of VLP-carriers may also be combined with an imaging/diagnostic option. In an interesting bioengineering approach, $\mathrm{Fe}_{3} \mathrm{O}_{4}$ nanoparticles were encapsulated into genetically engineered hepatitis B core $(\mathrm{HBc})$ virus-like particles through the specific affinity of histidine tags to the nickel nitrilotriacetic acid (NTA) chelate. ${ }^{21}$ The resulting HBc-144-His virus-like particles with loaded $\mathrm{Fe}_{3} \mathrm{O}_{4}$ nanoparticles were highly monodisperse and uniform (Figure 4). The encapsulation 
efficiency for the iron oxide nanoparticles into the virus-like cores was found to be strongly dependent on the core size. When assessed in an in vitro model of HeLa cells the obtained core-containing VLPs exhibited higher cellular uptake compared to the free iron oxide particles. These iron oxide particles may serve as contrast agents to visualize in vivo uptake at sites of infection. It would also be conceivable to encapsulate other metal nanoparticles such as gold into these VLPs to render theranostic carriers, for both therapy and diagnostic use. In any case, extended biocompatibility assessments will be required to evaluate whether this promising approach may be translated to preclinical studies.
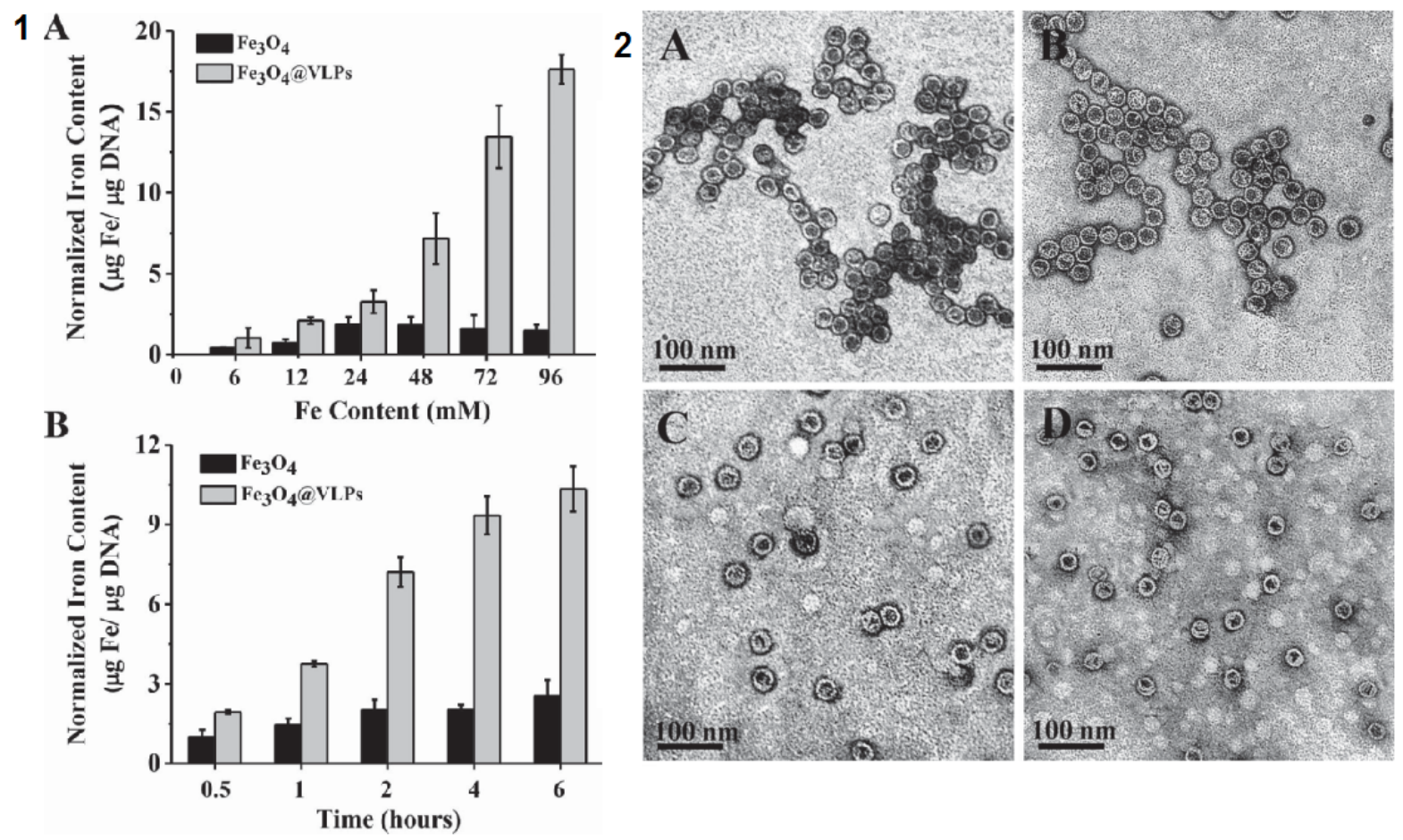

Figure 4. Genetically engineered hepatitis B core (HBc) virus-like particles (VLP) with a histidine tag rendered $\mathrm{HBc}-144-\mathrm{His}$ VLPs loaded with $\mathrm{Fe}_{3} \mathrm{O}_{4}-\mathrm{NTA}-\mathrm{Ni}^{2+}$ nanoparticles with various diameters. 1 (A and B). Their cellular uptake was assessed in HeLa cells. 2 (A-D). TEM images of negatively stained samples of engineered hepatitis $\mathrm{B}$ core virus-like particles loaded with $\mathrm{Fe}_{3} \mathrm{O}_{4}$. Reprinted with permission from Shen, L., Zhou, J., Wang, Y., Kang, N., Ke, X., Bi, S., and Ren, L. (2015) Efficient encapsulation of $\mathrm{Fe} 3 \mathrm{O} 4$ nanoparticles into genetically engineered hepatitis $\mathrm{B}$ core virus-like particles through a specific interaction for potential bioapplications. Small 11, 1190-1196. Copyright 2014 WILEY-VCH Verlag GmbH \& Co. KGaA, Weinheim.

In general, VLPs are not only promising for transport of drug compounds but even more interesting in developing safe vaccines that induce strong immune responses. They offer favorable properties regarding chemical and genetic modification but they are not self-replicative. A comprehensive overview on their bioengineering was recently published. ${ }^{30}$ 
Another strategy that has been investigated to overcome the bacterial resistance to antibiotics is the use of bacteriophages. Bacteriophages, or simply phages, have been used to treat infections for almost 100 years. ${ }^{31,32}$ Phages have several advantages over traditional antibiotic treatment, including selfamplification, low toxicity and species-specificity. ${ }^{32,33}$ In a hamster model, Nale et al. showed that the combination of phages on the treatment of Clostridium difficile limited its proliferation. In vitro, the combination of phages reduced $C$. difficile growth. ${ }^{34}$ The use of phages has also been linked to the restoration of antibiotic susceptibility in multi-drug-resistant Pseudomonas aeruginosa. ${ }^{35}$ The use of phage therapy has potential to eradicate infections by its sole use or by combination with traditional antibiotics. A comprehensive review on phage therapy has been recently published discussing the main challenges of this field. ${ }^{32}$

\section{Cell-hitchhiking approaches}

Red blood cells (RBCs) are natural, biocompatible and biodegradable delivery vehicles which have numerous properties that can inspire the development of biomimetic carriers. ${ }^{36}$ Their structure consists of a semi-permeable membrane that can release small-molecule drugs in a sustained pattern. They are able to encapsulate and protect cargos by forming compartments and can circulate in the body for a long period of time due to their non-immunogenic and biocompatible characteristics, ${ }^{36}$ both proven in clinical trials. ${ }^{37}$ The main challenge of using RBCs as a drug delivery system is loading them while maintaining their biological properties. ${ }^{38}$ There are now several methods for RBC encapsulation of drugs of choice, including the antibiotics primaquine ${ }^{39}$ and amikacin, ${ }^{40}$ which are summarized in a recent review. ${ }^{41}$

Another elegant avenue for using erythrocytes would be their surface modification with drugs or nanoparticles in a cellular hitchhiking concept (Figure 2). Anselmo and collaborators have attached polystyrene nanoparticles to the surface of mice RBCs to deliver drugs or particles to specific sites, such as the lung. Both were incubated at varying particle to RBC ratios (Figure 5). The nanoparticles remained attached to the RBCs under static conditions, but detached upon mimicking the shear stress present under physiological conditions (5 $\mathrm{Pa}$ for $15 \mathrm{~min}$ at $37{ }^{\circ} \mathrm{C}$ ), such as in the lung microvasculature. When the erythrocytes reach the capillaries in the lung, the nanoparticles detach 
from the RBCs, stick to the walls of the capillary and may be taken up by target cells. ${ }^{22}$ When loading nanoparticles with antibiotics of choice, this approach has potential to treat lung infection, such as persistent bacterial infections in cystic fibrosis patients. ${ }^{42}$ A major advantage of this technology is the simple isolation of $\mathrm{RBC}$ carriers from individual patients which may evoke even lower immunogenicity and facilitate a sort of individualized medicine approach to treat difficult lung infections.
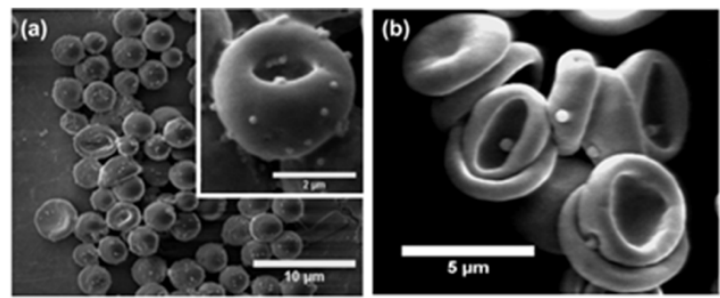

(e)
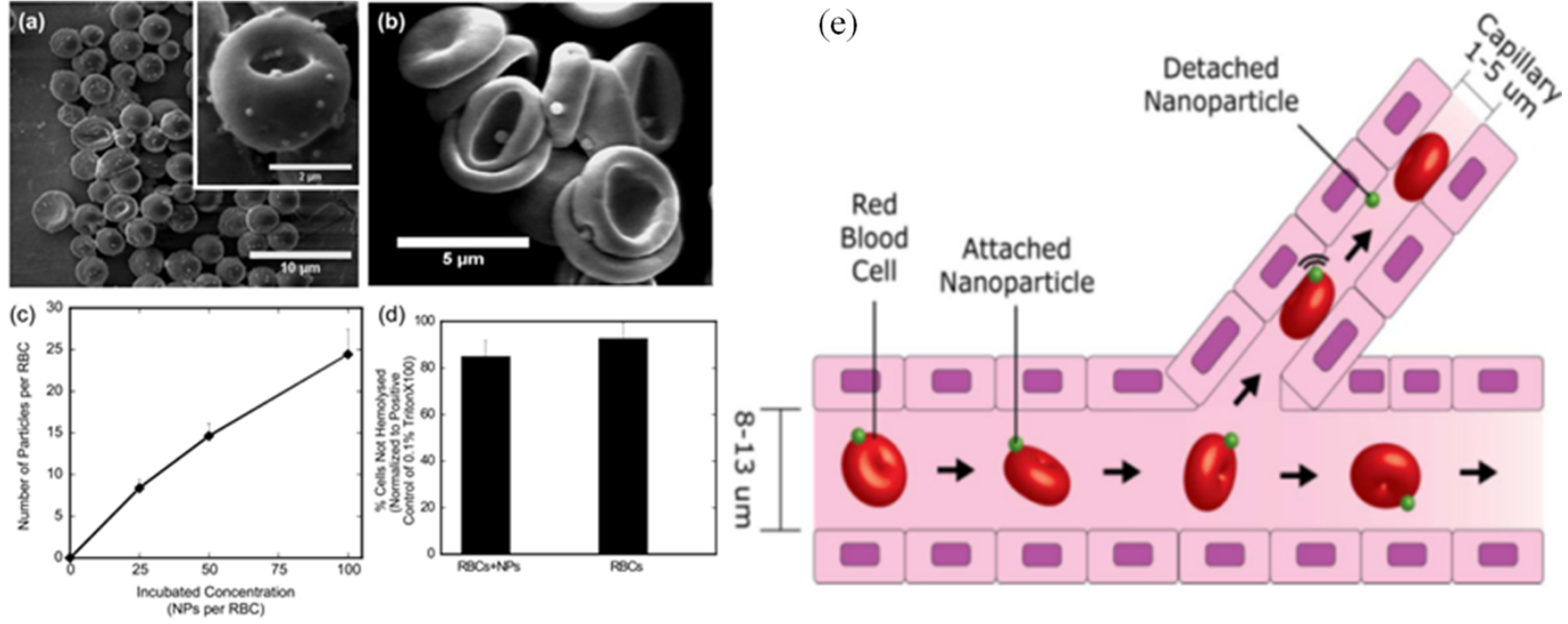

Figure 5. a) and b) Representative SEM images of polystyrene NPs attached to the surface of RBCs. c) Graph showing that the amount of NPs attached on the surface of RBCs is concentration dependent. d) The attachment of NPs to RBCs did not cause hemolysis. e) Schematic representation of the detachment of NPs from RBCs in tiny capillaries present in the lung microvasculature. Reprinted with permission from Anselmo, A. C., Gupta, V., Zern, B. J., Pan, D., Zakrewsky, M., Muzykantov, V., and Mitragotri, S. (2013) Delivering nanoparticles to lungs while avoiding liver and spleen through adsorption on red blood cells. ACS Nano 7, 11129-11137. Copyright 2013 American Chemical Society.

Immune cells, such as neutrophils, exhibit a natural affinity for and homing to inflamed and infected tissue, making them promising transfer avenues to carry diagnostic and therapeutic molecules to sites of infections. ${ }^{43}$ Drug-loaded, denatured albumin nanoparticles are often taken up by neutrophils that are activated and adherent to the blood vessel wall (Figure 6a). ${ }^{44} \mathrm{Chu}$ and coworkers demonstrated by intravital microscopy of mouse cremaster venules that these albumin-NPs were internalized by neutrophils, which subsequently transmigrated through the blood vessel wall and into the muscle to reach inflamed tissues. ${ }^{23}$ They showed that neutrophils carrying albumin NPs can cross the vessel barrier in an acute lung inflammation model in mice. ${ }^{23}$ To investigate the antimicrobial therapy potential of these albumin NPs-carrier neutrophils, the NPs were loaded with a 
broad spectrum antibiotic - cefoperazone acid - and tested against Pseudomonas aeruginosa lung infection in mice (Figure 6b). The antibiotic-loaded NPs did not impair the neutrophil mobility and activation or the lung integrity, but they reduced bacterial burden threefold compared to a free solution of cefoperazone acid. ${ }^{23}$ Although the biocompatibility and immune-stimulatory potential of these neutrophil carriers needs to be further assessed, this approach successfully exemplifies the potential of immune cells as natural carriers by exploiting their physiological mechanisms to deliver compounds to sites of infection and inflammation.
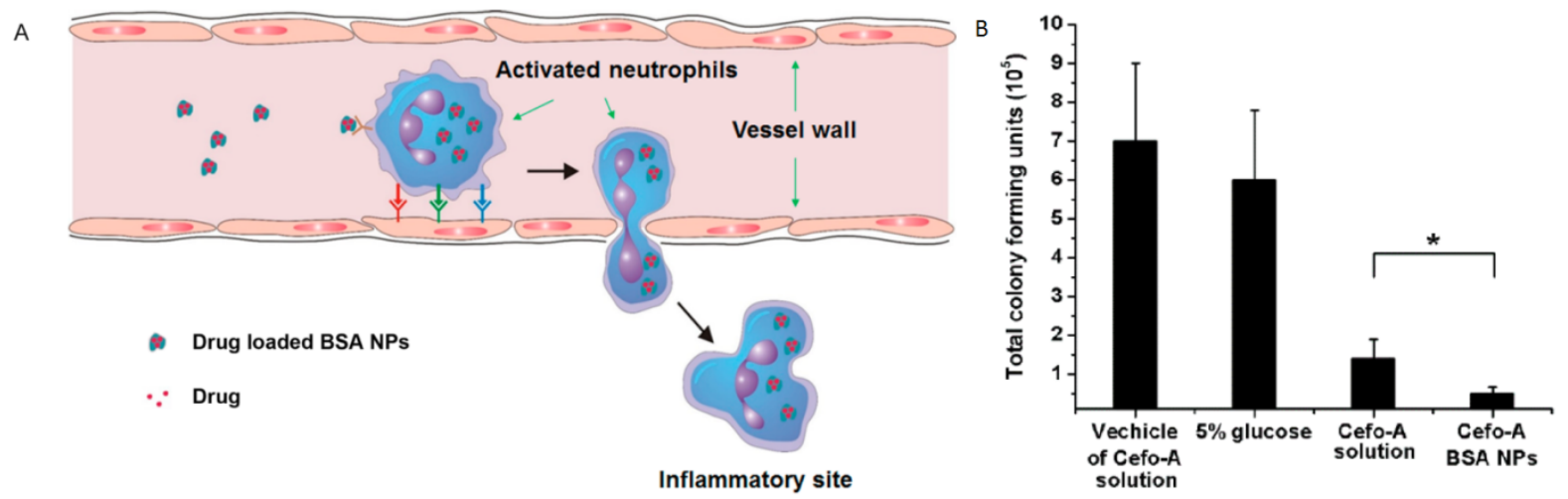

Figure 6. a) Schematic representation of the concept of neutrophil-mediated delivery. Activated neutrophils may actively transmigrate blood vessel walls and accumulate in inflammatory tissue. b) Albumin nanoparticles loaded with antibiotic cephoperazone acid (Cefo-A) NPs reduced bacterial proliferation of Pseudomonas aeruginosa threefold when compared to the free drug. Reprinted with permission from Chu, D., Gao, J., and Wang, Z. (2015) Neutrophil-Mediated Delivery of Therapeutic Nanoparticles across Blood Vessel Barrier for Treatment of Inflammation and Infection. ACS Nano 9, 11800-11811. Copyright 2015 American Chemical Society.

\section{- Natural and bioengineered particles as biogenic carriers for anti-infectives}

Extracellular vesicles for targeted drug transport

Extracellular vesicles (EVs) are natural nanoparticles produced by the majority of prokaryotic and eukaryotic cells. ${ }^{24,45}$ Initially, they were thought to be inert cellular debris, but they are increasingly recognized as playing important roles in intercellular communication. ${ }^{46}$ EVs are classified according to their biogenesis and size, dividing them mostly into two classes: exosomes, with a size range of 50-200 nm, and shedding microvesicles, that may have sizes of $100 \mathrm{~nm}$ up to several micrometers. ${ }^{25,47}$ Due to their structure - a lipid bilayer membrane containing proteins - they have been referred to as natural liposomes. ${ }^{25,47}$ They are postulated to have a natural role in 
transferring information between cells and tissues, thus their potential as drug carriers has been investigated for various applications ranging from inflammation, ${ }^{48}$ cancer, ${ }^{49}$ infections, ${ }^{25}$ and cardiovascular diseases. ${ }^{50}$ The use of EVs as drug carriers largely depends on effective methods of incorporating suitable drugs. ${ }^{51}$ It has been shown that they may be loaded with various compounds, such as small molecule drugs, enzymes and nucleic acids (Figure 2). ${ }^{52-54}$

Some EVs were shown to be inherently anti-infective. Using such preformed vesicles would take advantage of their physiological properties without extensive post-processing. In literature, there are examples for both EV-surface proteins and EV-contained compounds that induce such antimicrobial effect. When neutrophils are challenged with $S$. aureus, their microvesicles induce significantly better aggregation of exogenously added bacteria, compared to microvesicles from nonchallenged neutrophils. ${ }^{55}$

This aggregation was mediated by CD11 $\beta$-binding of bacteria onto the microvesicle surface, an effect that is also applied for infection diagnostics. A few recent examples have indicated that exosomes may also naturally contain anti-infective compounds, such as those isolated from urine of healthy humans contain proteins known to be bacteriostatic (e.g. mucin-1) and bactericidal (e.g. lysozyme C). ${ }^{56}$ Immunogold electron microscopy imaging revealed that these proteins are naturally loaded into EVs. After identifying these proteins in urinary exosomes, Hiemstra and collaborators investigated their ability to inhibit the growth of strains of $E$. coli that are responsible for urinary tract infections. The urinary exosomes were able to inhibit the growth of E. coli, ${ }^{56}$ suggesting that they play an important role in innate immunity. Indeed, exosomes induced bacterial lysis during $15 \mathrm{~min}$ of incubation with $E$. coli, suggesting release of their cargo in close proximity of bacteria but the detailed mechanism was not studied. Hu et al showed that nasal exosomes contain a number of proteins responsible for cell trafficking and present antibacterial properties. ${ }^{57}$ Using a Boyden chemotaxis chamber - a standard assay measuring cell migration through a porous membrane - it was revealed that immune cells isolated from blood migrate to the exosome-containing chamber. ${ }^{57}$ They also investigated exosomal proteins by exclusion list-based liquid chromatography-MS/MS and discovered that proteins with antifungal and antibacterial activity are decreased in patients that present respiratory diseases, such as asthma, when compared to healthy individuals. ${ }^{57}$ These results suggest 
that individuals who have pulmonary diseases might be more susceptible to infections and that exosomes contribute to an innate infection defense mechanism in healthy individuals. The focus of this study was on identification of exosomal proteins but it would be highly relevant to know more on the mechanism by which these EV induce antimicrobial activity. Hu et al also demonstrated the importance of exosomes in infections by assessing the release of biliary and intestinal epithelium EVs upon infection by Cryptosporidium parvum, a parasite. ${ }^{58}$ Exposure of the parasite to those exosomes decreased its viability and ability of infection in vitro in H69 human lung carcinoma cells and in urine cholangiocyte 603B cells, and in mice. ${ }^{58}$ These examples indicate a potential of physiological EVs to become an important delivery system for transferring natural or antibacterial cargos in a relevant infection setting. The exploration of the origin and therapeutic applicability of these EVs needs further evaluation, for example concerning the functional diversity of EV-subpopulations ${ }^{59}$, and will clarify whether the biogenic EV approach is a viable future strategy in the clinics. ${ }^{60}$

\section{Outer membrane vesicles as vaccines}

Bacteria are also able to produce EVs and, when they are gram-negative, these vesicles are called outer membrane vesicles (OMVs), while EVs produced by gram-positive bacteria are called membrane vesicles (MVs). ${ }^{61}$ Mycobacteria and fungi are also known to pinch off small vesicles but the mechanism for this is still debated. ${ }^{62}$ There are different examples of inherently antimicrobial OMVs that may attack other bacteria during the fight for environmental niches, such as from Pseudomonas aeruginosa ${ }^{63}$ or Myxococcus xanthus. ${ }^{64}$ The production of OMVs can be induced by the use of low concentrations of antibiotics during bacterial culture, but those OMVs are bigger than OMVs obtained at normal bacterial homeostasis. However, both particle types have the same content, such as the presence of enzymes which may degrade competing microbes. ${ }^{63}$ The immunogenicity of OMVs may be reduced by engineering of their lipopolysaccharide composition which is important for using them as biogenic carriers. ${ }^{65}$ Still, it is necessary to assess their biocompatibility under in vivo conditions to validate whether the use of bacteria-derived vesicles for treatment approaches is feasible. In contrast, OMVs have been studied in more detail for vaccine applications as they represent cell-free carriers displaying many relevant bacterial antigens. Such a non-replicative 
approach is highly promising and there are first formulations now in clinical assessment for meningitides therapy. ${ }^{66}$

\section{Bioengineered liposomes as carriers for antibiotics}

Some bacteria have invasion factors that facilitate their entrance into host cells. This is the case for Yersinia pseudotuberculosis, which uses a protein called invasin to enhance host cell attachment and uptake into epithelial cells via integrin binding. ${ }^{67}$ Inspired by this ability of invading microbes, Labouta and collaborators developed a liposome formulation functionalized with the $Y$. pseudotuberculosis invasion protein (InvA497) (Figure 2). InvA497 was coupled onto the surface of monodisperse phospholipid fluorescent liposomes ${ }^{26}$ and it was shown that the invasin-functionalized carriers had a higher cell adhesion and better cellular uptake compared to non-functionalized liposomes. The uptake studies indicated an active mechanism of internalization, mimicking the pathological uptake route of $Y$. pseudotuberculosis. ${ }^{26}$ In a follow-up study, Menina and collaborators showed that the invasin-functionalized liposomes loaded with the model antibiotic gentamycin had a greater antimicrobial effect on intracellular Y. pseudotuberculosis and Salmonella enterica in HEp-2 epithelial cells when compared to non-functionalized liposomes, due to their surface modification. ${ }^{27}$ This approach indicates that taking advantage of the natural bacterial invasion characteristics may aid in enhancing the antibacterial activity of drugs that have poor permeability, such as gentamycin. Nevertheless, it remains to be determined to which degree the functionalized liposomal carrier interacts with other gastrointestinal cells upon oral administration and whether or not invasin recognition is specific to enterocytes suffering from intracellular pathogens.

In another liposome-based approach, Henry and collaborators engineered vesicles with cholesterol and sphingomyelin that sequester pore-forming toxins produced by gram-positive bacteria, competing with host cells for toxin binding. ${ }^{68}$ Once they are bound to the liposomes, these toxins cannot lyse mammalian cells in vitro. ${ }^{68}$ Using an in vivo model, it was shown that engineered liposomes prevented S. aureus and S. pneumoniae septicemia within 10 hours after infection in mice.

${ }^{68}$ Moreover, when used in a combination treatment of engineered liposomes plus administration of antibiotic vancomycin, lethal effects caused by the infection of $S$. aureus and $S$. pneumoniae were 
successfully prevented in vivo. ${ }^{68}$ This impressive example shows that by exploiting naturally-derived principles, it is possible to create effective and simple therapy options for such yet challenging to treat septicemia. As several liposomal formulations have already been marketed for other dispositions, the translation of the present approach into clinical assessment may be facilitated.

- Bioengineered biomaterials for overcoming challenges associated with infections

Biomimetic approaches may also be combined with engineering techniques to create bioengineered materials to combat bacterial infections. ${ }^{69}$ One such approach is conjugation of molecules or proteins to natural or (semi)synthetic polymers, creating bioengineered drug-polymer conjugates. These conjugates have shown to exhibit enhanced stability under pulmonary ${ }^{70}$ or oral administration, ${ }^{71}$ indicating that this method may be feasible. A comprehensive overview discussing such orally administered bio-inspired approaches is summarized in a recent review manuscript. ${ }^{72}$ Hydrogels offer easily accessible chemical modifications and are often studied as bioinspired systems, as they may be tuned to render mechanical stiffness of living tissue or they may release their cargo in a trigger-dependent way. ${ }^{73}$ Thus, hydrogels have been shown to modulate cell behavior ${ }^{74}$ or to constitute biomechanical functions of native tissue. ${ }^{75}$

Hydrogels also offer the possibility for a localized and thus highly controlled application of biogenic and bioengineered approaches. A recent example of such an avenue is the development of a 3D-imprinted hydrogel to sequester bacterial $\beta$-lactamase. ${ }^{76} \beta$-lactamase is a bacterial enzyme and a known factor of increasing resistance and lack of efficiency of $\beta$-lactam antibiotics ${ }^{5}$. These enzymes may cleave and inactivate different classes of anti-infectives, such as penicillins or cephalosporins. In the present example, a hydrogel made of $\mathrm{N}$-isopropylacryl-amide was $\beta$-lactamase-imprinted. The resulting temperature-sensitive scaffold was able to selectively sequester $\beta$-lactamase enzymes, resulting in an increased susceptibility of bacteria towards conventional penicillin $G$ treatment. Successful application of the systems was shown both in vitro and in an animal model of wound infection. Bacterial growth in simulated wounds was abolished almost completely by using the imprinted gel in combination with antibiotic treatment. A major advantage of such approach is that it aims for an extra-bacterial factor which may overall reduce the evolution pressure on pathogens and 
thus the rate of occurrence of resistances. In general, extra-bacterial targets are a promising avenue to develop materials that less likely induce resistances in the long run. ${ }^{77}$ Different stimuli-responsive systems are currently explored for on-demand release of nanoantibiotics. ${ }^{78}$ One such approach are self-assembled vesicles with encapsulated antimicrobial agents. ${ }^{79}$ In presence of specific enzymes produced by resistant bacteria, vesicles would disintegrate and release their cargo in a selective manner. Probiotics and other non-pathogenic bacteria are not thought to be harmed. Although it only represents a bio-inspired approach, it is worth mentioning and may in the future help to achieve bacteria-selective killing without typical gastrointestinal side effects often associated with antiinfective therapy. In general, combining such approaches with novel biomimetic and bio-inspired materials may open further opportunities in fighting difficult-to-treat infections. Another example of such efforts is the development of a polysaccharide-based, biodegradable hydrogel that mimics glycosaminoglycans in the natural extracellular matrix. ${ }^{80}$ These hydrogels, composed of the natural polymers dextran and chitosan and loaded with vancomycin, have shown promising antimicrobial activity in vitro, indicating that they may be used as wound dressing. This approach combines the drug activity of antimicrobial agents with the anti-infective effect of natural chitosan which underlines the importance of biomaterials that show additional interactions with the target tissue.

Finally, another important issue in biomaterials research is to prevent infections on prosthetic surfaces during clinical application. These infections constitute important challenges concerning clinical implication of materials. In an effort to overcome such biomaterial-associated infections and biofilm formation, strategies that involve novel biomaterials have been investigated, such as the enzyme-mimicking polymer brush-functionalized surface that mimics DNase, an enzyme that prevents bacterial adhesion and subsequently, biofilm formation. ${ }^{81}$ The natural DNase, however, is very vulnerable, which impairs its performance in antibacterial applications, but the use of the DNasemimicking polymer brushes prolonged its bioactivity. ${ }^{81}$ Several other approaches to preventing infections on prosthetic biomaterials are summarized in a comprehensive review, but most of them are of (fully) synthetic origin and are thus beyond the scope of the present work. ${ }^{82}$

\section{- What is the future for biogenic approaches to tackle infectious diseases?}


The field of biogenic and bio-inspired approaches for treatment and diagnosis of infections is still young and thriving; we see it full of challenges but also promises. Many clinically established antimicrobial compounds are not efficient (anymore) and new drugs have yet to show biocompatibility and efficiency. Moreover, their tissue-selective delivery is very important, especially when antibiotics with strong side-effects come into play. In other fields of drug delivery research, such as cancer treatment, it can be seen that synthetic nanoparticles may improve the targeted transport of compounds only to a certain extent. ${ }^{83}$ Thus, we believe that using physiological, natural, biogenic systems is safer and possibly more efficient. ${ }^{84}$ Nature has developed and optimized these principles over millions of years of evolution and the examples discussed in this perspective show us that specific and selective interaction with target pathogens may be within reach. A bottleneck at the moment is the isolation and preparation of these nature-derived approaches in a reproducible and upscalable manner. Nevertheless, chemical synthesis may never replicate the chemical and biological complexity of these mechanisms that appear under physiological conditions, indicating that at the moment we have to rely on the available natural sources (e.g. red blood cells). Advanced biotechnological approaches for large cell culture and established production techniques for biomimetic carriers such as liposomes will be of avail when also taking biogenic avenues to the next step.

Another avenue of circumventing current issues with large scale production of biogenic systems would be their semi-synthetic bioengineering. We foresee that a combination of nature-derived systems and clinically established approaches is most promising to succeed in targeting future challenges in infection research, such as by creating cell-like hybrids ${ }^{85}$ or by developing hierarchically organized nano-materials. ${ }^{86}$ Such "joint partnership" has already been recommended for combining EV avenues with known liposomal principles to render next-generation delivery systems ${ }^{87}$ or to even create synthetic exosomes. ${ }^{88}$ Semi-synthetic EV-systems may be obtained in a biotechnologically controllable manner and would enhance their extended use. The combination of novel biogenic and bioengineered principles with responsive and intelligent biomaterials is another prerequisite to transform physiological avenues into real and applicable formulations and systems. Taking advantage of nature's exceptional ability to design novel responsive biomaterials to 
specifically target pathogenic bacteria will undoubtedly help to recuperate the anti-infective power of our current antibiotic arsenal for future anti-infective avenues.

\section{Acknowledgements}

This work was supported by the NanoMatFutur Junior Research programme from the Federal Ministry of Education and Research, Germany (grant number 13XP5029A). The authors acknowledge Eilien Schulz and Sara Menina for providing figures, Basant Eldessouki for her help with literature research and Bryan Weaver for proof-reading. 


\section{References}

(1) Parodi, A., Molinaro, R., Sushnitha, M., Evangelopoulos, M., Martinez, J. O., Arrighetti, N., Corbo, C., and Tasciotti, E. (2017) Bio-inspired engineering of cell- and virus-like nanoparticles for drug delivery. Biomaterials 147, 155-168. DOI 10.1016/j.biomaterials.2017.09.020.

(2) Yang, K. S., Im, H., Hong, S., Pergolini, I., Fernandez, A., Wang, R., Clardy, S., Huang, C., Pille, C., Ferrone, S., Yang, R., Castro, C. M., Lee, H., Fernandez, C., and Weissleder, R. (2017) Multiparametric plasma EV profiling facilitates diagnosis of pancreatic malignancy. Sci. Transnatl. Med. 9, 1-10. DOI 10.1126/scitranslmed.aal3226.

(3) Yoo, J.-W., Irvine, D. J., Discher, D. E., and Mitragotri, S. (2011) Bio-inspired, bioengineered and biomimetic drug delivery carriers. Nat. Rev. Drug Discov. 10, 521-535. DOI 10.1038/nrd3499.

(4) Dehaini, D., Fang, R. H., and Zhang, L. (2016) Biomimetic strategies for targeted nanoparticle delivery. Bioeng. Transl. Med. 1, 30-46. DOI 10.1002/btm2.10004.

(5) Blair, J. M. A., Webber, M. A., Baylay, A. J., Ogbolu, D. O., and Piddock, L. J. V. (2015) Molecular mechanisms of antibiotic resistance. Nat. Rev. Microbiol. 13, 42-51. DOI 10.1038/nrmicro3380.

(6) Perros, M. (2015) A sustainable model for antibiotics. Science 347, 1062-1064. DOI 10.1126/science.aaa3048.

(7) Wagner, S., Hauck, D., Hoffmann, M., Sommer, R., Joachim, I., Müller, R., Imberty, A., Varrot, A., and Titz, A. (2017) Covalent Lectin Inhibition and Application in Bacterial Biofilm Imaging. Angew. Chemie Int. Ed. 56, 16559-16564. DOI 10.1002/anie.201709368.

(8) Thomann, A., de Mello Martins, A. G. G., Brengel, C., Empting, M., and Hartmann, R. W. (2016) Application of Dual Inhibition Concept within Looped Autoregulatory Systems toward Antivirulence Agents against Pseudomonas aeruginosa Infections. ACS Chem. Biol. 11, 1279-1286. DOI 10.1021/acschembio.6b00117.

(9) Zazo, H., Colino, C. I., and Lanao, J. M. (2016) Current applications of nanoparticles in infectious diseases. J. Control. Release 224, 86-102. DOI 10.1016/j.jconrel.2016.01.008.

(10) Mofazzal Jahromi, M. A., Sahandi Zangabad, P., Moosavi Basri, S. M., Sahandi Zangabad, K., 
Ghamarypour, A., Aref, A. R., Karimi, M., and Hamblin, M. R. (2018) Nanomedicine and advanced technologies for burns: Preventing infection and facilitating wound healing. Adv. Drug Deliv. Rev. 123, 33-64. DOI 10.1016/j.addr.2017.08.001.

(11) Fuhrmann, G., Herrmann, I. K., and Stevens, M. M. (2015) Cell-derived vesicles for drug therapy and diagnostics: Opportunities and challenges. Nano Today 10, 397-409. DOI 10.1016/j.nantod.2015.04.004.

(12) Löffler, B., Tuchscherr, L., Niemann, S., and Peters, G. (2014) Staphylococcus aureus persistence in non-professional phagocytes. Int. J. Med. Microbiol. 304, 170-176. DOI 10.1016/j.ijmm.2013.11.011.

(13) Bjarnsholt, T., Ciofu, O., Molin, S., Givskov, M., and Høiby, N. (2013) Applying insights from biofilm biology to drug development-can a new approach be developed? Nat. Rev. Drug Discov. 12, 791-808. DOI 10.1038/nrd4000.

(14) Thet, N. T., Wallace, L., Wibaux, A., Boote, N., and Jenkins, A. T. A. (2018) Development of a mixed-species biofilm model and its virulence implications in device related infections. J. Biomed. Mater. Res. Part B Appl. Biomater. 1-9. DOI 10.1002/jbm.b.34103.

(15) Filkins, L. M., and O’Toole, G. A. (2015) Cystic Fibrosis Lung Infections: Polymicrobial, Complex, and Hard to Treat. PLoS Pathog. 11, 1-8. DOI 10.1002/jbm.b.34103.

(16) Forier, K., Raemdonck, K., De Smedt, S. C., Demeester, J., Coenye, T., and Braeckmans, K. (2014) Lipid and polymer nanoparticles for drug delivery to bacterial biofilms. J. Control. Release 190, 607-623. DOI 10.1016/j.jconrel.2014.03.055.

(17) Sheikhpour, M., Barani, L., and Kasaeian, A. (2017) Biomimetics in drug delivery systems: A critical review. J. Control. Release 253, 97-109. DOI 10.1016/j.jconrel.2017.03.026.

(18) Stanton, M. M., Park, B. W., Vilela, D., Bente, K., Faivre, D., Sitti, M., and Sánchez, S. (2017) Magnetotactic Bacteria Powered Biohybrids Target E. coli Biofilms. ACS Nano 11, 9968-9978. DOI 10.1021/acsnano.7b04128.

(19) Niu, Y., Yu, M., Hartono, S. B., Yang, J., Xu, H., Zhang, H., Zhang, J., Zou, J., Dexter, A., Gu, W., and Yu, C. (2013) Nanoparticles Mimicking Viral Surface Topography for Enhanced Cellular Delivery. Adv. Mater. 25, 6233-6237. DOI 10.1002/adma.201302737. 
(20) Ashley, C. E., Carnes, E. C., Phillips, G. K., Durfee, P. N., Buley, M. D., Lino, C. A., Padilla, D. P., Phillips, B., Carter, M. B., Willman, C. L., Brinker, C. J., Caldeira, J. D. C., Chackerian, B., Wharton, W., and Peabody, D. S. (2011) Cell-specific delivery of diverse cargos by bacteriophage MS2 virus-like particles. ACS Nano 5, 5729-5745. DOI 10.1021/nn201397z.

(21) Shen, L., Zhou, J., Wang, Y., Kang, N., Ke, X., Bi, S., and Ren, L. (2015) Efficient encapsulation of $\mathrm{Fe} 3 \mathrm{O} 4$ nanoparticles into genetically engineered hepatitis $\mathrm{B}$ core virus-like particles through a specific interaction for potential bioapplications. Small 11, 1190-1196. DOI 10.1002/smll.201401952. (22) Anselmo, A. C., Gupta, V., Zern, B. J., Pan, D., Zakrewsky, M., Muzykantov, V., and Mitragotri, S. (2013) Delivering nanoparticles to lungs while avoiding liver and spleen through adsorption on red blood cells. ACS Nano 7, 11129-11137. DOI 10.1021/nn404853z.

(23) Chu, D., Gao, J., and Wang, Z. (2015) Neutrophil-Mediated Delivery of Therapeutic Nanoparticles across Blood Vessel Barrier for Treatment of Inflammation and Infection. ACS Nano 9 , 11800-11811. DOI 10.1021/acsnano.5b05583.

(24) György, B., Hung, M. E., Breakefield, X. O., and Leonard, J. N. (2015) Therapeutic Applications of Extracellular Vesicles: Clinical Promise and Open Questions. Annu. Rev. Pharmacol. Toxicol. 55, 439-464. DOI 10.1146/annurev-pharmtox-010814-124630.

(25) Fuhrmann, G., Neuer, A. L., and Herrmann, I. K. (2017) Extracellular vesicles - A promising avenue for the detection and treatment of infectious diseases? Eur. J. Pharm. Biopharm. 118, 56-61. DOI 10.1016/j.ejpb.2017.04.005.

(26) Labouta, H. I., Menina, S., Kochut, A., Gordon, S., Geyer, R., Dersch, P., and Lehr, C. M. (2015) Bacteriomimetic invasin-functionalized nanocarriers for intracellular delivery. J. Control. Release 220, 414-424. DOI 10.1016/j.jconrel.2015.10.052.

(27) Menina, S., Hagar, A., Labouta, I., Geyer, R., Krause, T., Gordon, S., Dersch, P., and Lehr, C.M. (2016) Invasin-functionalized liposome nanocarriers improve the intracellular delivery of antiinfective drugs. $R S C A d v .6,41622-41629$. DOI 10.1039/c6ra02988d.

(28) Taherkhani, S., Mohammadi, M., Daoud, J., Martel, S., and Tabrizian, M. (2014) Covalent binding of nanoliposomes to the surface of magnetotactic bacteria for the synthesis of self-propelled therapeutic agents. ACS Nano 8, 5049-5060. DOI 10.1021/nn5011304. 
(29) Park, B. W., Zhuang, J., Yasa, O., and Sitti, M. (2017) Multifunctional Bacteria-Driven Microswimmers for Targeted Active Drug Delivery. ACS Nano 11, 8910-8923. DOI 10.1021/acsnano.7b03207.

(30) Mohsen, M. O., Zha, L., Cabral-Miranda, G., and Bachmann, M. F. (2017) Major findings and recent advances in virus-like particle (VLP)-based vaccines. Semin. Immunol. 34, 123-132. DOI 10.1016/j.smim.2017.08.014.

(31) Chanishvili, N. (2012) Phage Therapy-History from Twort and d'Herelle Through Soviet Experience to Current Approaches, in Advances in Virus Research 1st ed., pp 3-40. Elsevier Inc. DOI 10.1016/B978-0-12-394438-2.00001-3.

(32) Lin, D. M., Koskella, B., and Lin, H. C. (2017) Phage therapy: An alternative to antibiotics in the age of multi-drug resistance. World J. Gastrointest. Pharmacol. Ther. 8, 162. DOI 10.4292/wjgpt.v8.i3.162.

(33) Bourdin, G., Navarro, A., Sarker, S. A., Pittet, A. C., Qadri, F., Sultana, S., Cravioto, A., Talukder, K. A., Reuteler, G., and Brüssow, H. (2014) Coverage of diarrhoea-associated Escherichia coli isolates from different origins with two types of phage cocktails. Microb. Biotechnol. 7, 165-176. DOI 10.1111/1751-7915.12113.

(34) Nale, J. Y., Spencer, J., Hargreaves, K. R., Buckley, A. M., and Trzepin, P. (2016) Bacteriophage Combinations Significantly Reduce Clostridium difficile Growth In Vitro and Proliferation In Vivo Bacteriophage Combinations Significantly Reduce Clostridium difficile Growth In Vitro and Proliferation In Vivo. Antimicrob. Agents Chemother. 60, 968-981. DOI 10.1128/AAC.01774-15.

(35) Chan, B. K., Sistrom, M., Wertz, J. E., Kortright, K. E., Narayan, D., and Turner, P. E. (2016) Phage selection restores antibiotic sensitivity in MDR Pseudomonas aeruginosa. Sci. Rep. 6, 1-8. DOI $10.1038 /$ srep26717.

(36) Hu, C. M. J., Fang, R. H., and Zhang, L. (2012) Erythrocyte-inspired delivery systems. $A d v$. Healthc. Mater. 1, 537-547. DOI 10.1002/adhm.201200138.

(37) Godfrin, Y., Horand, F., Franco, R., Dufour, E., Kosenko, E., Bax, B. E., Banz, A., Skorokhod, O. A., Lanao, J. M., Vitvitsky, V., Sinauridze, E., Bourgeaux, V., and Gunter, K. C. (2012) International seminar on the red blood cells as vehicles for drugs. Expert Opin. Biol. Ther. 12, $127-$ 
133. DOI 10.1517/14712598.2012.631909.

(38) Favretto, M. E., Cluitmans, J. C. A., Bosman, G. J. C. G. M., and Brock, R. (2013) Human erythrocytes as drug carriers: Loading efficiency and side effects of hypotonic dialysis, chlorpromazine treatment and fusion with liposomes. J. Control. Release 170, 343-351. DOI 10.1016/j.jconrel.2013.05.032.

(39) Alanazi, F. K., Harisa, G. E. D. I., Maqboul, A., Abdel-Hamid, M., Neau, S. H., and Alsarra, I. A. (2011) Biochemically altered human erythrocytes as a carrier for targeted delivery of primaquine: An in vitro study. Arch. Pharm. Res. 34, 563-571. DOI 10.1007/s12272-011-0406-7.

(40) Gutiérrez Millán, C., Zarzuelo Castañeda, A., González López, F., Sayalero Marinero, M. L., Lanao, J. M., and Arévalo, M. (2005) Encapsulation and in vitro evaluation of amikacin-loaded erythrocytes. Drug Deliv. J. Deliv. Target. Ther. Agents 12, 409-416. DOI

$10.1080 / 10717540590968909$.

(41) Sun, Y., Su, J., Liu, G., Chen, J., Zhang, X., Zhang, R., Jiang, M., and Qiu, M. (2017) Advances of blood cell-based drug delivery systems. Eur. J. Pharm. Sci. 96, 115-128. DOI 10.1016/j.ejps.2016.07.021.

(42) Sherrard, L. J., Tunney, M. M., and Elborn, J. S. (2014) Antimicrobial resistance in the respiratory microbiota of people with cystic fibrosis. Lancet (London, England) 384, 703-13. DOI 10.1016/S0140-6736(14)61137-5.

(43) Timin, A. S., Litvak, M. M., Gorin, D. A., Atochina-Vasserman, E. N., Atochin, D. N., and Sukhorukov, G. B. (2018) Cell-Based Drug Delivery and Use of Nano-and Microcarriers for Cell Functionalization. Adv. Healthc. Mater. 7, 1700818. DOI 10.1002/adhm.201700818.

(44) Wang, Z., Li, J., Cho, J., and Malik, A. B. (2014) Prevention of vascular inflammation by nanoparticle targeting of adherent neutrophils. Nat. Nanotechnol. 9, 204-210. DOI 10.1038/nnano.2014.17.

(45) EL Andaloussi, S., Mäger, I., Breakefield, X. O., and Wood, M. J. A. (2013) Extracellular vesicles: biology and emerging therapeutic opportunities. Nat. Rev. Drug Discov. 12, 347-357. DOI 10.1038/nrd3978.

(46) Camussi, G., Deregibus, M. C., Bruno, S., Cantaluppi, V., and Biancone, L. (2010) 
Exosomes/microvesicles as a mechanism of cell-to-cell communication. Kidney Int. 78, 838-848. DOI 10.1038/ki.2010.278.

(47) Armstrong, J. P. K., Holme, M. N., and Stevens, M. M. (2017) Re-Engineering Extracellular Vesicles as Smart Nanoscale Therapeutics. ACS Nano 11, 69-83. DOI 10.1021/acsnano.6b07607. (48) Sun, D., Zhuang, X., Xiang, X., Liu, Y., Zhang, S., Liu, C., Barnes, S., Grizzle, W., Miller, D., and Zhang, H. G. (2010) A novel nanoparticle drug delivery system: The anti-inflammatory activity of curcumin is enhanced when encapsulated in exosomes. Mol. Ther. 18, 1606-1614. DOI 10.1038/mt.2010.105.

(49) Samuel, P., Fabbri, M., and Carter, D. R. F. (2017) Mechanisms of Drug Resistance in Cancer: The Role of Extracellular Vesicles. Proteomics 17, 1600375. DOI 10.1002/pmic.201600375. (50) Bei, Y., Das, S., Rodosthenous, R. S., Holvoet, P., Vanhaverbeke, M., Monteiro, M. C., Monteiro, V. V. S., Radosinska, J., Bartekova, M., Jansen, F., Li, Q., Rajasingh, J., and Xiao, J. (2017) Extracellular vesicles in cardiovascular theranostics. Theranostics 7, 4168-4182. DOI $10.7150 /$ thno. 21274 .

(51) García-Manrique, P., Matos, M., Gutiérrez, G., Pazos, C., and Blanco-López, M. C. (2018) Therapeutic biomaterials based on extracellular vesicles: classification of bio-engineering and mimetic preparation routes. J. Extracell. Vesicles 7, 1422676. DOI 10.1080/20013078.2017.1422676. (52) Fuhrmann, G., Serio, A., Mazo, M., Nair, R., and Stevens, M. M. (2015) Active loading into extracellular vesicles significantly improves the cellular uptake and photodynamic effect of porphyrins. J. Control. Release 205, 35-44. DOI 10.1016/j.jconrel.2014.11.029.

(53) Somiya, M., Yoshioka, Y., and Ochiya, T. (2017) Drug delivery application of extracellular vesicles; insight into production, drug loading, targeting, and pharmacokinetics. AIMS Bioeng. 4, 7392. DOI 10.3934/bioeng.2017.1.73.

(54) Haney, M. J., Klyachko, N. L., Zhao, Y., Gupta, R., Plotnikova, E. G., He, Z., Patel, T., Piroyan, A., Sokolsky, M., Kabanov, A. V., and Batrakova, E. V. (2015) Exosomes as drug delivery vehicles for Parkinson's disease therapy. J. Control. Release 207, 18-30. DOI 10.1016/j.jconrel.2015.03.033. (55) Herrmann, I. K., Bertazzo, S., O’Callaghan, D. J. P., Schlegel, A. A., Kallepitis, C., Antcliffe, D. B., Gordon, A. C., and Stevens, M. M. (2015) Differentiating sepsis from non-infectious systemic 
inflammation based on microvesicle-bacteria aggregation. Nanoscale 7, 13511-13520. DOI 10.1039/ C5NR01851J.

(56) Hiemstra, T. F., Charles, P. D., Gracia, T., Hester, S. S., Gatto, L., Al-Lamki, R., Floto, R. A., Su, Y., Skepper, J. N., Lilley, K. S., and Karet Frankl, F. E. (2014) Human Urinary Exosomes as Innate Immune Effectors. J. Am. Soc. Nephrol. 25, 2017-2027. DOI 10.1681/ASN.2013101066. (57) Lässer, C., O’Neil, S. E., Shelke, G. V., Sihlbom, C., Hansson, S. F., Gho, Y. S., Lundbäck, B., and Lötvall, J. (2016) Exosomes in the nose induce immune cell trafficking and harbour an altered protein cargo in chronic airway inflammation. J. Transl. Med. 14, 181. DOI 10.1186/s12967-016$0927-4$.

(58) Hu, G., Gong, A.-Y., Roth, A. L., Huang, B. Q., Ward, H. D., Zhu, G., LaRusso, N. F., Hanson, N. D., and Chen, X.-M. (2013) Release of Luminal Exosomes Contributes to TLR4-Mediated Epithelial Antimicrobial Defense. PLoS Pathog. (Petri, W. A., Ed.) 9, e1003261. DOI 10.1371/journal.ppat.1003261.

(59) Tkach, M., Kowal, J., and Théry, C. (2018) Why the need and how to approach the functional diversity of extracellular vesicles. Philos. Trans. R. Soc. Lond. B. Biol. Sci. 373, 20160479. DOI 10.1098/rstb.2016.0479.

(60) Fais, S., O’Driscoll, L., Borras, F. E., Buzas, E., Camussi, G., Cappello, F., Carvalho, J., Cordeiro da Silva, A., Del Portillo, H., El Andaloussi, S., Ficko Trček, T., Furlan, R., Hendrix, A., Gursel, I., Kralj-Iglic, V., Kaeffer, B., Kosanovic, M., Lekka, M. E., Lipps, G., Logozzi, M., Marcilla, A., Sammar, M., Llorente, A., Nazarenko, I., Oliveira, C., Pocsfalvi, G., Rajendran, L., Raposo, G., Rohde, E., Siljander, P., van Niel, G., Vasconcelos, M. H., Yáñez-Mó, M., Yliperttula, M. L., Zarovni, N., Zavec, A. B., and Giebel, B. (2016) Evidence-Based Clinical Use of Nanoscale Extracellular Vesicles in Nanomedicine. ACS Nano 10, 3886-3899. DOI 10.1021/acsnano.5b08015. (61) Manning, A. J., and Kuehn, M. J. (2013) Functional advantages conferred by extracellular prokaryotic membrane vesicles. J. Mol. Microbiol. Biotechnol. 23, 131-141. DOI $10.1159 / 000346548$.

(62) Brown, L., Wolf, J. M., Prados-Rosales, R., and Casadevall, A. (2015) Through the wall: Extracellular vesicles in Gram-positive bacteria, mycobacteria and fungi. Nat. Rev. Microbiol. 13, 
620-630. DOI 10.1038/nrmicro3480.

(63) Kadurugamuwa, J. L., and Beveridge, T. J. (1996) Bacteriolytic effect of membrane vesicles from Pseudomonas aeruginosa on other bacteria including pathogens: conceptually new antibiotics $178,2767-2774$

(64) Evans, A. G. L., Davey, H. M., Cookson, A., Currinn, H., Cooke-Fox, G., Stanczyk, P. J., and Whitworth, D. E. (2012) Predatory activity of Myxococcus xanthus outer-membrane vesicles and properties of their hydrolase cargo. Microbiology 158, 2742-2752. DOI 10.1099/mic.0.060343-0.

(65) Baker, J. L., Chen, L., Rosenthal, J. A., Putnam, D., and DeLisa, M. P. (2014) Microbial biosynthesis of designer outer membrane vesicles. Curr. Opin. Biotechnol. 29, 76-84. DOI 10.1016/j.copbio.2014.02.018.

(66) Kaparakis-Liaskos, M., and Ferrero, R. L. (2015) Immune modulation by bacterial outer membrane vesicles. Nat. Rev. Immunol. 15, 375-387. DOI 10.1038/nri3837.

(67) Dersch, P., and Isberg, R. R. (2000) An immunoglobulin superfamily-like domain unique to the Yersinia pseudotuberculosis invasin protein is required for stimulation of bacterial uptake via integrin receptors. Infect. Immun. 68, 2930-2938. DOI 10.1128/IAI.68.5.2930-2938.2000.

(68) Henry, B. D., Neill, D. R., Becker, K. A., Gore, S., Bricio-Moreno, L., Ziobro, R., Edwards, M. J., Mühlemann, K., Steinmann, J., Kleuser, B., Japtok, L., Luginbühl, M., Wolfmeier, H., Scherag, A., Gulbins, E., Kadioglu, A., Draeger, A., and Babiychuk, E. B. (2014) Engineered liposomes sequester bacterial exotoxins and protect from severe invasive infections in mice. Nat. Biotechnol. 33, 81-88. DOI 10.1038/nbt.3037.

(69) Wohl, B. M., Smith, A. A. A., Jensen, B. E. B., and Zelikin, A. N. (2014) Macromolecular (pro)drugs with concurrent direct activity against the hepatitis $\mathrm{C}$ virus and inflammation. J. Control. Release 196, 197-207. DOI 10.1016/j.jconrel.2014.09.032.

(70) Das, D., Chen, J., Srinivasan, S., Kelly, A. M., Lee, B., Son, H.-N., Radella, F., West, T. E., Ratner, D. M., Convertine, A. J., Skerrett, S. J., and Stayton, P. S. (2017) Synthetic Macromolecular Antibiotic Platform for Inhalable Therapy against Aerosolized Intracellular Alveolar Infections. Mol. Pharm. 14, 1988-1997. DOI 10.1021/acs.molpharmaceut.7b00093.

(71) Matoori, S., Fuhrmann, G., and Leroux, J.-C. (2013) Celiac Disease: A Challenging Disease for 
Pharmaceutical Scientists. Pharm. Res. 30, 619-626. DOI 10.1007/s11095-012-0951-x.

(72) Fuhrmann, K., and Fuhrmann, G. (2017) Recent advances in oral delivery of macromolecular drugs and benefits of polymer conjugation. Curr. Opin. Colloid Interface Sci. 31, 67-74. DOI 10.1016/j.cocis.2017.07.002.

(73) Fuhrmann, G., Chandrawati, R., Parmar, P. A., Keane, T. J., Maynard, S. A., Bertazzo, S., and Stevens, M. M. (2018) Engineering Extracellular Vesicles with the Tools of Enzyme Prodrug Therapy. Adv. Mater. 1706616. DOI 10.1002/adma.201706616.

(74) Santos, L., Fuhrmann, G., Juenet, M., Amdursky, N., Horejs, C.-M., Campagnolo, P., and Stevens, M. M. (2015) Extracellular Stiffness Modulates the Expression of Functional Proteins and Growth Factors in Endothelial Cells. Adv. Healthc. Mater. 4, 2056-2063. DOI 10.1002/adhm.201500338.

(75) Parmar, P. A., Chow, L. W., St-Pierre, J. P., Horejs, C. M., Peng, Y. Y., Werkmeister, J. A., Ramshaw, J. A. M., and Stevens, M. M. (2015) Collagen-mimetic peptide-modifiable hydrogels for articular cartilage regeneration. Biomaterials 54, 213-225. DOI 10.1016/j.biomaterials.2015.02.079. (76) Li, W., Dong, K., Ren, J., and Qu, X. (2016) A $\beta$-Lactamase-Imprinted Responsive Hydrogel for the Treatment of Antibiotic-Resistant Bacteria. Angew. Chemie Int. Ed. 55, 8049-8053. DOI 10.1002/ anie. 201600205 .

(77) Allen, R. C., Popat, R., Diggle, S. P., and Brown, S. P. (2014) Targeting virulence: can we make evolution-proof drugs? Nat. Rev. Microbiol. 12, 300-308. DOI 10.1038/nrmicro3232.

(78) Crucho, C. I. C. (2018) The Attack of the Smart Particles: Should Bacteria Be Afraid? ACS Med. Chem. Lett. 9, 2-3. DOI 10.1021/acsmedchemlett.7b00455.

(79) Li, Y., Liu, G., Wang, X., Hu, J., and Liu, S. (2016) Enzyme-Responsive Polymeric Vesicles for Bacterial-Strain-Selective Delivery of Antimicrobial Agents. Angew. Chemie Int. Ed. 55, 1760-1764. DOI 10.1002/anie.201509401.

(80) Zhao, Y., Zhang, X., Wang, Y., Wu, Z., An, J., Lu, Z., Mei, L., and Li, C. (2014) In situ crosslinked polysaccharide hydrogel as extracellular matrix mimics for antibiotics delivery. Carbohydr. Polym. 105, 63-69. DOI 10.1016/j.carbpol.2014.01.068.

(81) Jiang, R., Xin, Z., Xu, S., Shi, H., Yang, H., Song, L., Yan, S., Luan, S., Yin, J., Khan, A. F., and 
Li, Y. (2017) Enzyme-mimicking polymer brush-functionalized surface for combating biomaterialassociated infections. Appl. Surf. Sci. 423, 869-880. DOI 10.1016/j.apsusc.2017.06.232.

(82) Campoccia, D., Montanaro, L., and Arciola, C. R. (2013) A review of the biomaterials technologies for infection-resistant surfaces. Biomaterials 34, 8533-8554. DOI 10.1016/j.biomaterials.2013.07.089.

(83) Wilhelm, S., Tavares, A. J., Dai, Q., Ohta, S., Audet, J., Dvorak, H. F., and Chan, W. C. W. (2016) Analysis of nanoparticle delivery to tumours. Nat. Rev. Mater. 1, 16014. DOI 10.1038/natrevmats.2016.14.

(84) Le, N. T., Kalluri, J. R., Loni, A., Canham, L. T., and Coffer, J. L. (2017) Biogenic Nanostructured Porous Silicon as a Carrier for Stabilization and Delivery of Natural Therapeutic Species. Mol. Pharm. 14, 4509-4514. DOI 10.1021/acs.molpharmaceut.7b00638.

(85) Xiao, Q., Yadavalli, S. S., Zhang, S., Sherman, S. E., Fiorin, E., da Silva, L., Wilson, D. A., Hammer, D. A., André, S., Gabius, H.-J., Klein, M. L., Goulian, M., and Percec, V. (2016) Bioactive cell-like hybrids coassembled from (glyco)dendrimersomes with bacterial membranes. Proc. Natl. Acad. Sci. 113, E1134-E1141. DOI 10.1073/pnas.1525589113.

(86) Wang, C. X., Braendle, A., Menyo, M. S., Pester, C. W., Perl, E. E., Arias, I., Hawker, C. J., and Klinger, D. (2015) Catechol-based layer-by-layer assembly of composite coatings: a versatile platform to hierarchical nano-materials. Soft Matter 11, 6173-6178. DOI 10.1039/C5SM01374G. (87) Johnsen, K. B., Gudbergsson, J. M., Duroux, M., Moos, T., Andresen, T. L., and Simonsen, J. B. (2018) On the use of liposome controls in studies investigating the clinical potential of extracellular vesicle-based drug delivery systems - A commentary. J. Control. Release 269, 10-14. DOI 10.1016/j.jconrel.2017.11.002.

(88) García-Manrique, P., Gutiérrez, G., and Blanco-López, M. C. (2018) Fully Artificial Exosomes: Towards New Theranostic Biomaterials. Trends Biotechnol. 36, 10-14. DOI 10.1016/j.tibtech.2017.10.005. 
TOC graphic

Biogenic and biomimetic carriers as versatile transporters to treat infections

Adriely Goes and Gregor Fuhrmann

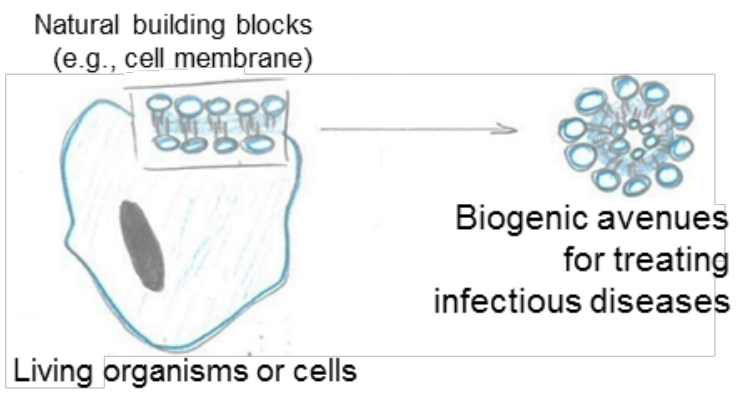

